Jansen, A.P.D., Hout, H.P.J. van, Nijpels, G., Rijmen, F., Droës, R.M., Pot, A.M., Schellevis, F.G., Stalman, W.A.B., Marwijk, H.W.J. van. Effectiveness of case management among older adults with early symptoms of dementia and their primary informal caregivers: a randomized clinical trial. International Journal of Nursing Studies: 2011, 48(8), 933-943

\begin{tabular}{|l|l|}
\hline Postprint Version & 1.0 \\
\hline Journal website & $\underline{\mathrm{http} / / \mathrm{dx} . \text { doi.org/10.1016/j.ijnurstu.2011.02.004 }}$ \\
\hline Pubmed link & $\underline{\mathrm{http} / / / \text { www.ncbi.nlm.nih.gov/pubmed/21356537 }}$ \\
\hline DOI & $10.1016 /$ j.ijnurstu.2011.02.004 \\
\hline
\end{tabular}

This is a NIVEL certified Post Print, more info at http://www.nivel.eu

\title{
Effectiveness of case management among older adults with early symptoms of dementia and their primary informal caregivers: A randomized clinical trial
}

\author{
AALTJE P.D. JANSEN ${ }^{A, B}$, , HeIN P.J. VAN HOUT ${ }^{A, B}$, GIEL NIJPELS ${ }^{A, B}$, FRANK RIJMEN ${ }^{A, C}$, ROSE-MARIE \\ DRÖES $^{\text {A, D, E }}$, ANNE-MARGRIET POT ${ }^{\mathrm{A}, \mathrm{D}, \mathrm{F}}$, FRANÇOIS G. SCHELLEVIS ${ }^{\mathrm{A}, \mathrm{B}, \mathrm{G}}$, WIM A.B. STALMAN ${ }^{\mathrm{A}, \mathrm{B}}$ AND HARM \\ W.J. VAN MARWIJK ${ }^{\mathrm{A}, \mathrm{B}}$ \\ ${ }^{a}$ EMGO Institute for Health and Care Research, VU University Medical Center, Amsterdam, The \\ Netherlands \\ ${ }^{\mathrm{b}}$ Department of General Practice, VU University Medical Center, Amsterdam, The Netherlands \\ ${ }^{c}$ Department of Biostatistics, VU University Medical Center, Amsterdam, The Netherlands \\ ${ }^{\mathrm{d}}$ Department of Psychiatry/Alzheimer Center, VU University Medical Center, Amsterdam, The Netherlands \\ e Department of Nursing Home Medicine, VU University Medical Center, Amsterdam, The Netherlands \\ ${ }^{\mathrm{f}}$ Trimbos-institute, Netherlands Institute of Mental Health and Addiction, Utrecht, The Netherlands \\ ${ }^{g}$ Nivel, Netherlands Institute for Health Services Research, Utrecht, The Netherlands
}

\begin{abstract}
Background: It is believed that timely recognition and diagnosis of dementia is a pre-condition for improving care for both older adults with dementia and their informal caregivers. However, diagnosing dementia often occurs late in the disease. This means that a significant number of patients with early symptoms of dementia and their informal caregivers may lack appropriate care.

Objectives :To compare the effects of case management and usual care among communitydwelling older adults with early symptoms of dementia and their primary informal caregivers. Design : Randomized controlled trial with measurements at baseline and after 6 and 12 months. Setting :Primary care in West-Friesland, the Netherlands. Participants: 99 pairs of community-dwelling older adults with dementia symptoms (defined as abnormal screening for symptoms of dementia) and their primary informal caregivers.

Intervention: 12 months of case management by district nurses for both older adults and informal caregivers versus usual care.

Measurements:Primary outcome: informal caregiver's sense of competence. Secondary outcomes: caregiver's quality of life, depressive symptoms, and burden, and patient's quality of life. Process measurements: intervention fidelity and caregiver's satisfaction with the quality of case management.

Results:Linear mixed model analyses showed no statistically significant and clinically relevant differences over time between the two groups. The process evaluation revealed that
\end{abstract}


Jansen, A.P.D., Hout, H.P.J. van, Nijpels, G., Rijmen, F., Droës, R.M., Pot, A.M., Schellevis, F.G., Stalman, W.A.B., Marwijk, H.W.J. van. Effectiveness of case management among older adults with early symptoms of dementia and their primary informal caregivers: a randomized clinical trial. International Journal of Nursing Studies: 2011

intervention fidelity could have been better. Meanwhile, informal caregivers were satisfied with the quality of case management.

Conclusion:This study shows no benefits of case management for older adults with dementia symptoms and their primary informal caregivers. One possible explanation is that case management, which has been recommended among diagnosed dementia patients, may not be beneficial if offered too early. However, on the other hand, it is possible that: (1) case management will be effective in this group if more fully implemented and adapted or aimed at informal caregivers who experience more severe distress and problems; (2) case management is beneficial but that it is not seen in the timeframe studied; (3) case management might have undetected small benefits. This has to be established.

\section{WHAT IS ALREADY KNOWN ABOUT THE TOPIC?}

- Diagnosing dementia often occurs late in the disease.

- For many informal caregivers caring for a person suffering from dementia has adverse financial, physical, social, and psychological consequences.

- It is believed that timely recognition and diagnosis of dementia is a pre-condition for improving care for both older adults with dementia and their caregivers.

- In Europe, case management is recommended among community-dwelling diagnosed dementia patients and their caregivers, but not among persons with abnormal screening for symptoms of dementia and their caregivers.

\section{WHAT THIS PAPER ADDS}

- This randomized controlled trial demonstrates that older adults with abnormal screening for symptoms of dementia and their caregivers did not benefit of case management. The 12 month, nurse-led, case management intervention offered no benefits above usual care with respect to caregiver's sense of competence, quality of life, depressive symptoms and burden, and patient's quality of life.

\section{BACKGROUND}

The growing number of older adults with dementia and its associated increasing health care utilization are experienced as problems worldwide, as well as the prevalent adverse financial, physical, social, and psychological consequences for the informal caregivers (Torti et al., 2004).

It is believed that timely recognition and diagnosis of dementia is a pre-condition for improving care for both older adults with dementia and their caregivers (Vernooij-Dassen et al., 2005). However, diagnosing dementia often occurs late in the disease process (Vernooij-Dassen et al., 2005). This means that a significant number of community-dwelling older adults with early symptoms of dementia and their caregivers may lack appropriate care.

However, up till now, studies evaluating interventions among these persons are lacking. In contrast to this situation, large numbers of studies have evaluated interventions among caregivers of community-dwelling older adults with diagnosed dementia. Meta-analyses and reviews have shown that multi-component interventions that provide caregivers with diverse services and individually tailored interventions are the most effective programs ([Acton and Kang, 2001], [Brodaty et al., 2003] and [Pusey and Richards, 2001]). Meanwhile, reviews of the effects of health, social and psychological interventions on caregiver's psychological well-being and burden are inconclusive ([Schoenmakers et al., 2010], [Selwood et al., 2007] and [Thompson et al., 2007]).

Case management has been associated with reductions in burden and depression (Newcomer et al., 1999), improvements in well-being and distress ([Callahan et al., 2006], [Challis et al., 2002] and [Specht et al., 2009]). In Europe, case management has been recommended among community-dwelling diagnosed dementia patients and their caregivers (Alzheimer Europe, 2008). Offering case management to early recognized patients and their caregivers as well may prevent prevalent adverse consequences of caregiving on well-being and quality of life. 
Jansen, A.P.D., Hout, H.P.J. van, Nijpels, G., Rijmen, F., Droës, R.M., Pot, A.M., Schellevis, F.G., Stalman, W.A.B., Marwijk, H.W.J. van. Effectiveness of case management among older adults with early symptoms of dementia and their primary informal caregivers: a randomized clinical trial. International Journal of Nursing Studies: 2011

The objective of this randomized controlled trial was to determine the effects of case management among community-dwelling older adults with dementia symptoms (defined as abnormal screening for symptoms of dementia) and their primary informal caregivers.

It was hypothesized that during a period of one year:

- Caregivers in the case management group would improve on sense of competence and quality of life, and would experience less depressive symptoms and burden, while those in the usual care group would remain stable or decline on these outcomes.

- Care recipients in the case management group would improve on quality of life, while those in the usual care group would be stable or decline on this outcome.

\section{METHODS}

\subsection{Design}

A randomized controlled trial was conducted with random assignment of participants to either case management by district nurses or usual care. Potential participants were sent an information letter by mail and were asked to sign an informed consent form. In case people were incompetent their representatives were asked to give informed consent. The Medical Ethics Committee of the VU University medical center in Amsterdam approved the study protocol. The study protocol has been described elsewhere in detail (Jansen et al., 2005).

\subsection{Participants and setting}

Detection of older adults with dementia symptoms and subsequent recruitment and trial entry of these persons and their informal caregivers took place among primary care practitioners (PCPs) in WestFriesland, the Netherlands.

In the Netherlands, PCPs are the first persons to visit in case of a health problem. They are gatekeepers in the Dutch health care system, controlling access to specialized care. Virtually all people are registered in a general practice.

\subsubsection{Detection}

Detection occurred in three ways:

(1) 55 PCPs sent the Informant Questionnaire on Cognitive Decline (IQCODE) (

Jorm and Jacomb, 1989) to their general practice patients who were 75 years of age or older $(n=4823)$;

(2) 44 PCPs also identified persons suspected of dementia among the persons they had approached;

(3) a primary care Diabetic Research Center sent the IQCODE to older diabetic adults, who were 65 years of age or older, and who had not been approached by their PCP $(n=1480)$.

Persons with an IQCODE score of 3.6 and over (strongly suggesting cognitive decline) or who were suspected of dementia by their PCP underwent two cognitive tests: the Mini Mental State Examination (MMSE) (Folstein et al., 1975) and the 7 Minute Screen (7MS) (Solomon et al., 1998).

\subsubsection{Trial entry}

Persons were eligible for trial entry if they had scores on the MMSE (Folstein et al., 1975) below 24 or a risk of dementia of 50\% or more according to the 7MS (Solomon et al., 1998) and if a primary caregiver was present. The primary caregiver was defined as the caregiver who spent most hours on the caring process and/or who coordinated the caring process. Exclusion criteria for patients applied at baseline were assistance by an outpatient geriatric or psychiatric team for cognitive problems, terminal illness, insufficient command of the Dutch language, participation in other research projects, and institutionalization. Exclusion criteria for caregivers were terminal illness, providing less than $1 \mathrm{~h}$ of care a week, and insufficient command of the Dutch language.

\subsection{Randomization and blinding}

Randomization took place after the baseline measurements. An external independent person established the random order using random number tables (per practice). Participants knew that two different interventions were studied and they were informed about group assignment. PCPs and interviewers were 
Jansen, A.P.D., Hout, H.P.J. van, Nijpels, G., Rijmen, F., Droës, R.M., Pot, A.M., Schellevis, F.G., Stalman, W.A.B., Marwijk, H.W.J. van. Effectiveness of case management among older adults with early symptoms of dementia and their primary informal caregivers: a randomized clinical trial. International Journal of Nursing Studies: 2011

blinded to group assignment unless participants revealed their allocation. Researchers were blinded until they finished analyzing data.

\subsection{Interventions}

\subsubsection{Case management}

During one year, three district nurses who were specialized in geriatric care, acted as case managers. The nurses had mainly a coordinating function consisting of assessment, giving advice and information, planning, coordinating, organizing collaboration, and monitoring of care.

The nurses started the intervention with a home-visit in which they administered the Resident Assessment Instrument Home Care (RAI-HC) (Landi et al., 2000). The RAI-HC is a computerized multidimensional instrument that consists of a Minimum Data Set, which assesses the general functioning of the patient, and Client Assessment Protocols, providing protocols for the management of 30 potential and actual problem areas. Together with the participants, the nurses ordered the problems identified into a hierarchy of importance, and they formulated a care plan. Subsequently, they left behind a form to register care and the agreements made with health care professionals.

In the second home-visit, the nurses explored the caregiver's situation with a capacity and burden questionnaire (KITTZ, 1997) to formulate a care plan. They handed a guide holding available social and welfare services.

After these two visits, the nurses and participants decided how to proceed. When more visits were not considered necessary, the nurses contacted the participants at least every 3 months by telephone to monitor their situation. In addition, the nurses were available for consultation by telephone. The nurses visited the PCPs to inform them about the participants' situation.

Apart from these standard activities, the intervention held some tailor-made activities. For instance, the nurses referred patients and caregivers to other health care professionals, including diagnostic services, and they monitored the anticipated effect. In addition, the nurses organized family-meetings aimed at educating relatives, improving social support and relieving the primary caregiver (Mittelman et al., 2003).

The nurses were trained in working with RAI-HC and in organizing family-meetings. They also attended seminars on how to deal with dementia patients and their caregivers. They met monthly to discuss innovations and geriatric cases while supervised by a staff member of their home care organization.

\subsubsection{Usual care}

Usual care in the Netherlands comprehends a diversity of health care and welfare services. Participating pairs received care depending on their own initiative. They had no access to family meetings, nor were they offered an assessment with the RAI-HC, because these supportive activities are not offered regularly in the Netherlands.

\subsubsection{Measurements}

Outcomes were assessed by means of interviews and caregiver-completed questionnaires at baseline and after 6 and 12 months.

Primary outcome was caregiver's sense of competence measured with the three subscales of the Sense of Competence Questionnaire (SCQ; with higher scores indicating better sense of competence) (VernooijDassen et al., 1999): consequences of involvement in care for the personal life of the caregiver (scores ranging from 8 to 40), satisfaction with one's own performance as a caregiver (12-60) and satisfaction with the care recipient (7-35).

Secondary outcomes were caregiver's quality of life, measured with the MOS 36-item Short-Form health survey (SF-36) (McHorney et al., 1993), caregiver's depressive symptoms determined with the Center for Epidemiologic Studies Depression Scale (CES-D) (0-60) (Radloff, 1977), burden measured with the SelfPerceived Pressure by Informal Care (SPPIC) (0-9) (Pot et al., 1995), patient's quality of life measured with the subscales self-esteem, positive affect, negative affect, feelings of belonging, sense of aesthetics, and overall perception on quality of life of the Dementia Quality of Life Instrument (DQOL) (1-5) (Brod et al., 1999). 
Jansen, A.P.D., Hout, H.P.J. van, Nijpels, G., Rijmen, F., Droës, R.M., Pot, A.M., Schellevis, F.G., Stalman, W.A.B., Marwijk, H.W.J. van. Effectiveness of case management among older adults with early symptoms of dementia and their primary informal caregivers: a randomized clinical trial. International Journal of Nursing Studies: 2011

Apart from these outcomes, we assessed the following variables of the caregiver at baseline: sociodemographic characteristics (age, gender, educational level, relation with the care recipient, (not) living together with the care recipient), months spent on caring, hours spent on caring a week, help from other persons, functioning in activities of daily living (ADL) and instrumental activities of daily living (IADL) measured with the Groningen Activity Restriction Scale (GARS) (18-72) (Kempen et al., 1996), presence of chronic diseases, mastery over one's life measured with the Mastery Scale (7-35) (Pearlin and Schooler, 1978), caregiver's distress due to patient's behavioral problems measured with the distress-subscale of the Neuropsychiatric Inventory (NPI-Q) (0-60) (Kaufer et al., 2000), and social support measured with the social support list (SSL-I, subscale positive interactions) (34-136) (Bridges et al., 2002). On patient level at baseline we assessed socio-demographic characteristics (age, gender, last job level), presence of chronic diseases, patient's initiative to perform self-care (0-36) and patient's actual performance of self-care (0-44) measured with the Interview for Deterioration in Daily living activities in Dementia (IDDD) (Teunisse and Derix, 1991), behavioral problems measured with the Neuropsychiatric Inventory (NPI-Q) (0-36) (Kaufer et al., 2000), and urinary incontinence. Health care utilization of pairs was measured continuously by means of caregivers' self-reports.

\subsection{Sample size calculation}

Sample size calculations were based on dichotomized sum-scores on the SCQ reported for informal caregivers of patients with diagnosed dementia (mean 17.9, SD 5.2, range 4-27) (Vernooij-Dassen, 1993). Data on the SCQ in our target group were lacking. Calculations were based on $\alpha=0.05$ (two-tailed) and a desired power of 0.80 . For an anticipated effect of $15 \%$ difference in final scores of sense of competence after 12 months between the case management group and usual care group, and with improved scores in the case management group and stable scores in the usual care group, 37 persons per group were required. We expected a drop out rate of about $25 \%$ during the one-year follow-up, resulting in a total of 100 patients and caregivers to be included in the study (Statpower).

\subsection{Analysis}

Firstly, baseline similarity was studied. Secondly, baseline characteristics of dropouts and completers were compared by logistic regression analysis. Thirdly, linear mixed models (SPSS) with an unstructured covariance type were used to analyze differences over time in outcomes between the two groups. Linear mixed models have become the standard tool to analyze longitudinal data and permit the inclusion of participants with missing data (Fitzmaurice et al., 2004). Potential confounding due to baseline differences was checked by adding these variables as covariates in the analyses. Apart from the analyses with the two treatment groups we performed analyses using four groups (i.e. usual care, nurse 1, nurse 2, and nurse 3). Furthermore, we did three subgroup analyses for being a spouse of the care-recipient (yes/no), for living with the care recipient (yes/no) and for caregiver's gender.

Data were analyzed according to the intention-to-treat principle. Additionally, intensity-analyses were performed. Initially, data were planned to be analyzed according to the per-protocol principle. However, due to diversity in adherence to the several elements of the protocol this was not feasible and subsequently data were analyzed according to the intensity of the intervention across three groups. Participants in the case management group were divided into groups with more or less than $10 \mathrm{~h}$ of case management as a proxy intensity measure.

\subsection{Process evaluation}

\subsubsection{Intervention fidelity}

Assessments revealed whether or not participants were offered the intervention as designed:

(1) At the end of the study, caregivers marked the elements of the intervention they had been offered in the past year on a list with 13 obligatory and 3 tailor-made elements. A sum score of the obligatory elements offered was calculated. Differences in intervention fidelity across the nurses were analyzed using the Kruskal-Wallis test.

(2) Intervention fidelity of the nurses was revealed by means of semi-structured qualitative interviews with the nurses. Interviews were audio-taped and constructed by one researcher (AJ). Transcription was carried out to a level that included words and speech particles. Firstly, open coding was applied to each transcribed 
Jansen, A.P.D., Hout, H.P.J. van, Nijpels, G., Rijmen, F., Droës, R.M., Pot, A.M., Schellevis, F.G., Stalman, W.A.B., Marwijk, H.W.J. van. Effectiveness of case management among older adults with early symptoms of dementia and their primary informal caregivers: a randomized clinical trial. International Journal of Nursing Studies: 2011

interview. Two researchers (HH and AJ) independently read each transcription. Based on these interviews, a scheme was made with elements of the intervention (not) executed as designed by the three nurses.

(3) Hours spent on case management by the district nurses, based on registrations of the nurses' home care organization. Differences between the three nurses were analyzed using ANOVA.

\subsubsection{Informal caregivers' satisfaction with the quality of care}

Caregivers' satisfaction was measured with the QUality Of Care Through the patients' Eyes (QUOTEelderly) questionnaire (Sixma et al., 2000).

\section{RESULTS}

\subsection{Participants}

Between February 2004 and June 2005, 99 pairs of informal caregivers and care recipients were enrolled in the study in three ways:

(1) 72 care recipients, aged 75 years or older, were identified by means of the IQCODE sent by their PCP and subsequent cognitive testing;

(2) 7 care recipients, aged 75 years or older, were suspected of dementia by their PCP and identified by subsequent cognitive testing. They had not responded to the IQCODE or they had responded but were not identified by means of the IQCODE;

(3) 20 care recipients, aged 65 years or older, were identified by means of the IQCODE sent by a primary care Diabetic Research Center and subsequent cognitive testing.

\section{[FIGURE 1]}

Finally, 81 participating pairs were retained in the trial at 12 months. No differences appeared between the proportion of withdrawals in the case management group (8/54) and in the usual care group (3/45); difference in risk: $0.08,95 \%$ CI $[-0.63,0.79]$. Spousal pairs were more likely to withdraw than other pairs $(\mathrm{OR}=4.5,95 \% \mathrm{CI}: 1.11-18.2)$. Among the 81 pairs that completed all measurements, 70 pairs registered data on health care utilization.

Table 1 shows the baseline characteristics of participants. The characteristics were largely similar for the two groups except for caregiver's perceived social support $(\mathrm{t}=2.483 ; \mathrm{P}=.015)$, the number of months with cognitive symptoms according to the caregiver (Mann-Whitney's $\mathrm{U}=353.00 ; \mathrm{P}=.003$ ) and caregiver's satisfaction with the older adult as a recipient of care $(\mathrm{t}=2.093 ; \mathrm{P}=.039)$. Participating caregivers reported relatively few consequences of involvement in care for the personal life of the caregiver, and little distress due to patients' behavioral problems, as well as low severity of behavioral problems in patients.

\section{[TABLE 1]}

\subsection{Effectiveness of case management}

\subsubsection{Intention-to-treat analyses}

Linear mixed model analyses among the 99 participating pairs revealed no differences in the course over time between the two groups on caregiver's sense of competence, quality of life, depressive symptoms, and burden and patient's quality of life. Table 2 shows that all outcomes were stable over time in both groups, with the exception of patient's sense of aesthetics (DQoL), caregivers' satisfaction with the older adult as a recipient of care (SCQ) and consequences of involvement in care for the personal life of the caregiver (SCQ), which declined over time in both groups.

\section{[TABLE 2]}

No confounding due to baseline differences appeared. Furthermore, no other effects revealed when we repeated the same analyses with four groups (usual care, nurse 1, nurse 2, and nurse 3 ) and when we performed the three subgroup analyses.

The outcomes of the intensity-analyses were similar to those of the intention-to-treat analyses. 
Jansen, A.P.D., Hout, H.P.J. van, Nijpels, G., Rijmen, F., Droës, R.M., Pot, A.M., Schellevis, F.G., Stalman, W.A.B., Marwijk, H.W.J. van. Effectiveness of case management among older adults with early symptoms of dementia and their primary informal caregivers: a randomized clinical trial. International Journal of Nursing Studies: 2011

\subsection{Contrast in health care utilization}

During the 12 months, apart from case management by district nurses, no other differences were found in utilization between the two groups (see Table 3).

\section{[TABLE 3]}

\subsection{Delivery of the case management intervention}

51 pairs accepted the initial and second home visit. Table A shows the RAI modules triggered at the initial home visit. 45 pairs accepted care until the end of the trial (Fig. 1).

(1) Intervention fidelity reported by informal caregivers

The nurses implemented on average 11 out of the 13 obligatory elements (range $4-13 ; n=24$ out of 43 caregivers). They did not differ in the number of elements implemented $\left(\chi^{2}=2.914, \mathrm{df}=2, \mathrm{P}=0.233\right)$.

(2) Intervention fidelity reported by nurses

Table 4 shows elements of the intervention (not) executed by the nurses. Nurses often did not appraise the intervention as necessary yet for the participants.

\section{[TABLE 4]}

(3) Hours spent on case management

The nurses spent a mean time of $10.8 \mathrm{~h}$ a year per patient-caregiver pair on the intervention (range 0.75

$28 \mathrm{~h}$ ). The nurses differed in mean time spent on the intervention per pair; nurse 1 spent $8.8 \mathrm{~h}$ (range 2-26), nurse 2 spent $5.5 \mathrm{~h}$ (range $0.75-15$ ), and nurse 3 spent $15.2 \mathrm{~h}$ (range 9.6-28); $\mathrm{F}=9.811, \mathrm{P}<.001$.

\subsection{Informal caregivers' satisfaction with the quality of care of the intervention}

Table 4 shows the results of the QUOTE $(n=38)$. Overall, caregivers were satisfied with the quality of the intervention. They reported quality aspects that could be improved further: care coordination and time spent on consultations.

\section{DisCUSSION}

This study shows no benefits of case management for older adults with dementia symptoms and their primary caregivers.

\subsection{Methodological considerations}

Many requirements for a high quality trial were met. Both groups were largely similar at baseline, the contrast in utilization of case management between the two groups was reached, dropout rates were low for this vulnerable target group (18\%), and contamination was unlikely.

Participating PCPs $(n=55)$ represent all PCPs $(n=70)$ in the region Westfriesland. Usual care of all these PCPs is highly comparable. Participating pairs represent all pairs meeting inclusion criteria and willing to accept care. All eligible pairs were asked to participate and virtually all Dutch people are registered in a general practice.

Limitations of this study concern the sample size and power. Firstly, the study is sufficiently powered to detect a large effect, but not to detect a small effect. Secondly, sample size calculations were based on suboptimal data as data for our target group was lacking. In addition, calculations were based on dichotomized sum-scores on the SCQ instead of not-dichotomized sum-scores on the three subscales of the SCQ. However, a re-estimation showed that we succeeded in retaining enough participants in the trail to detect a large effect. This estimation was based on the baseline measurements of the subscale 'Consequences of involvement in care for the personal life of the caregiver' (mean 28.9, SD 6.8, range 840 ), $\alpha=0.05$ (two-tailed), a desired power of 0.80, an anticipated difference in mean values between the two groups of 4 points on a 33 point scale, and an equation adjusted with an indication of the correlation between the repeated measurements (i.e. 0.7) because of the longitudinal design (Twisk, 2003). A total of 78 patients and caregivers had to retain into the trial.

\subsection{Considerations on the intervention}

The intervention may have lacked sufficient intensity and duration to establish a change in outcomes. Poor intervention fidelity is another possible reason for not finding any surplus value of case management above 
Jansen, A.P.D., Hout, H.P.J. van, Nijpels, G., Rijmen, F., Droës, R.M., Pot, A.M., Schellevis, F.G., Stalman, W.A.B., Marwijk, H.W.J. van. Effectiveness of case management among older adults with early symptoms of dementia and their primary informal caregivers: a randomized clinical trial. International Journal of Nursing Studies: 2011

usual care. Poor intervention fidelity in turn, may have been influenced by characteristics of participants and the content of the intervention. The intervention may not have been relevant yet for the target group who reports relatively few consequences of involvement in care for the personal life of the caregiver, little distress and low severity of behavioral problems in patients. The intervention may have been more suitable for caregivers and older adults already experiencing more severe problems. To illustrate, the nurses did not appraise case management as necessary yet for all of the participants. This may have hampered providing a good rational for the delivery of case management and may have contributed to the fact that the intervention was not delivered as designed. However, poor intervention fidelity is common and other studies suggest that activities to further improve adherence to key care processes may lead to better quality of care and participant outcomes ([Vickrey et al., 2006] and [Cherry et al., 2004]).

\subsection{Comparison with other studies}

To our knowledge this is the first RCT to determine the effects of case management among communitydwelling older adults with dementia symptoms and their primary informal caregivers. Therefore, only comparison with studies among diagnosed patients and their caregivers is possible. Although we have implemented the most effective elements of interventions among these persons (i.e. multi-component and individually tailored) ([Acton and Kang, 2001], [Brodaty et al., 2003] and [Pusey and Richards, 2001]) in our case management program, we found no benefits of case management over usual care.

In conclusion, this study shows no benefits of case management for older adults with dementia symptoms and their primary informal caregivers. One possible explanation is that case management, which has been recommended among diagnosed dementia patients, may not be beneficial if offered too early. However, on the other hand, it is possible that: (1) case management will be effective in this group if more fully implemented and adapted or aimed at informal caregivers who experience more severe distress and problems; (2) case management is beneficial but that it is not seen in the timeframe studied; (3) case management might have undetected small benefits. This has to be established.

\section{ACKNOWLEDGEMENTS}

The authors like to thank all participating older adults and their informal caregivers, the nurses, the PCPs, the interviewers, the research-assistants Willemijn Tybout, Evelyn Mulder and Paulien Hoekstra, and Home Care Organization 'De Omring' for their cooperation.

Conflict of interest: None declared.

Funding: The Netherlands Organisation for Health Research and Development (ZonMw) kindly supported this study (ZonMw Grant No. 2200.0114). We proposed the study to ZonMw, and after that, the sponsors had no say in the conduct of the study or in the preparation of the paper.

Ethical approval: Ethical approval was given by the VU University medical center in Amsterdam, judgement's reference number 2002/104.

\section{REFERENCES}

Alzheimer Europe, 2008 Alzheimer Europe, Alzheimer in Europe Yearbook 2008, Alzheimer Europe (2008).

Acton and Kang, 2001 G.J. Acton and J. Kang, Interventions to reduce the burden of caregiving for an adult with dementia: a meta-analysis, Res. Nurs. Health 24 (5) (2001), pp. 349-360.

Bridges et al., 2002 K.R. Bridges, R. Sanderman and E. Van Sonderen, An English language version of the social support list: preliminary reliability, Psychol. Rep. 90 (3 Pt 1) (2002), pp. 1055-1058.

Brod et al., 1999 M. Brod, A.L. Steward, L. Sands and P. Walton, Conceptualization and measurement of quality of life in dementia: the dementia quality of life instrument (DQoL), The Gerontologist 39 (1999), pp. 25-35.

Brodaty et al., $2003 \mathrm{H}$. Brodaty, A. Green and A. Koschera, Meta-analysis of psychosocial interventions for caregivers of people with dementia, J. Am. Geriatr. Soc. 51 (5) (2003), pp. 657-664.

Callahan et al., 2006 C.M. Callahan, M.A. Boustani, F.W. Unverzagt, M.G. Austrom, T.M. Damush, A.J. Perkins, B.A. Fultz, S.L. Hui, S.R. Counsell and H.C. Hendrie, Effectiveness of collaborative care for older adults with Alzheimer disease in primary care: a randomized controlled trial, JAMA 295 (18) (2006), pp.

2148-2157. 
Jansen, A.P.D., Hout, H.P.J. van, Nijpels, G., Rijmen, F., Droës, R.M., Pot, A.M., Schellevis, F.G., Stalman, W.A.B., Marwijk, H.W.J. van. Effectiveness of case management among older adults with early symptoms of dementia and their primary informal caregivers: a randomized clinical trial. International Journal of Nursing Studies: 2011

Challis et al., 2002 D. Challis, R. von Abendorff, P. Brown, J. Chesterman and J. Hughes, Care management, dementia care and specialist mental health services: an evaluation, Int. J. Geriatr. Psychiatry 17 (4) (2002), pp. 315-325.

Cherry et al., 2004 D.L. Cherry, B.G. Vickrey, L. Schwankovsky, E. Heck, M. Plauchm and R. Yep, Interventions to improve quality of care: the Kaiser Permanente-Alzheimer's Association Dementia Care Project, Am. J. Manag. Care 10 (8) (2004), pp. 553-560.

Fitzmaurice et al., 2004 G.M. Fitzmaurice, N.M. Laird and J.H. Ware, Applied Longitudinal Analysis, John Wiley \& Sons (2004).

Folstein et al., 1975 M. Folstein, S. Folstein and P. McHugh, "Mini-Mental" State: a practical method for grading the cognitive state of patients for the clinician, J. Psychiatr. Res. 12 (1975), pp. 189-198.

Jansen et al., 2005 A.P. Jansen, H.P. van Hout, H.W. van Marwijk, G. Nijpels, M.C. de Bruijne, J.E. Bosmans, A.M. Pot and W.A. Stalman, (Cost)-effectiveness of case-management by district nurses among primary informal caregivers of older adults with dementia symptoms and the older adults who receive informal care: design of a randomized controlled trial [ISCRTN83135728], BMC Public Health 5 (2005), p. 133.

Jorm and Jacomb, 1989 A.F. Jorm and P.A. Jacomb, The Informant Questionnaire on Cognitive Decline in the Elderly (IQCODE): socio-demographic correlates, reliability, validity and some norms, Psychol. Med. 19 (4) (1989), pp. 1015-1022.

Kaufer et al., 2000 D.I. Kaufer, J.L. Cummings, P. Ketchel, V. Smith, A. MacMillan, T. Shelley, O.L. Lopez and S.T. DeKosky, Validation of the NPI-Q, a brief clinical form of the Neuropsychiatric Inventory, J. Neuropsychiatry Clin. Neurosci. 12 (2) (2000), pp. 233-239.

Kempen et al., 1996 G.I. Kempen, I. Miedema, J. Ormel and W. Molenaar, The assessment of disability with the Groningen Activity Restriction Scale. Conceptual framework and psychometric properties, Soc. Sci. Med. 43 (11) (1996), pp. 1601-1610.

KITTZ, 1997 KITTZ, Capacity and burden questionnaire for primary caregivers, Gorcum \& Comp., Groningen (1997) (in Dutch).

Landi et al., 2000 F. Landi, E. Tua, G. Onder, B. Carrara, A. Sgadari, C. Rinaldi, G. Gambassi, F. Lattanzio and R. Bernabei, Minimum data set for home care: a valid instrument to assess frail older people living in the community, Med. Care 38 (12) (2000), pp. 1184-1190.

McHorney et al., 1993 C.A. McHorney, J.E. Ware Jr. and A.E. Raczek, The MOS 36-Item Short-Form Health Survey (SF-36): II. Psychometric and clinical tests of validity in measuring physical and mental health constructs, Med. Care 31 (3) (1993), pp. 247-263.

Mittelman et al., 2003 M. Mittelman, C. Epstein and A. Pierzchala, Counseling the Alzheimer's Caregiver: A Resource for Health Care Professionals, AMA Press, Chicago (2003).

Newcomer et al., 1999 R. Newcomer, C. Yordi, R. DuNah, P. Fox and A. Wilkinson, Effects of the Medicare Alzheimer's Disease Demonstration on caregiver burden and depression, Health Serv. Res. 34 (3) (1999), pp. 669-689.

Pearlin and Schooler, 1978 L.I. Pearlin and C. Schooler, The structure of coping, J. Health Soc. Behav. 19 (1) (1978), pp. 2-21.

Pot et al., 1995 A.M. Pot, R. van Dyck and D.J. Deeg, Perceived stress caused by informal caregiving. Construction of a scale, Tijdschr. Gerontol. Geriatr. 26 (5) (1995), pp. 214-219.

Pusey and Richards, $2001 \mathrm{H}$. Pusey and D. Richards, A systematic review of the effectiveness of psychosocial interventions for carers of people with dementia, Aging Ment. Health 5 (2) (2001), pp. 107119.

Radloff, 1977 L.S. Radloff, The CES-D Scale: a self-report depression scale for research in the general population, Appl. Psychol. Meas. 1 (1977), pp. 385-401.

Selwood et al., 2007 A. Selwood, K. Johnston, C. Katona, C. Lyketsos and G. Livingston, Systematic review of the effect of psychological interventions on family caregivers of people with dementia, J. Affect. Disord. 101 (1-3) (2007), pp. 75-89.

Sixma et al., 2000 H.J. Sixma, C. van Campen, J.J. Kerssens and L. Peters, Quality of care from the perspective of elderly people: the QUOTE-elderly instrument, Age Ageing 29 (2000), pp. 173-178.

Schoenmakers et al., 2010 B. Schoenmakers, F. Buntinx and J. Delepeleire, Supporting the dementia family caregiver: the effect of home care intervention on general well-being, Aging Ment. Health 14 (1) (2010), pp. 44-56.

Solomon et al., 1998 P.R. Solomon, A. Hirschoff, B. Kelly, M. Relin, M. Brush, R.D. DeVeaux and W.W. Pendlebury, A 7 minute neurocognitive screening battery highly sensitive to Alzheimer's disease, Arch. Neurol. 55 (3) (1998), pp. 349-355. 
Jansen, A.P.D., Hout, H.P.J. van, Nijpels, G., Rijmen, F., Droës, R.M., Pot, A.M., Schellevis, F.G., Stalman, W.A.B., Marwijk, H.W.J. van. Effectiveness of case management among older adults with early symptoms of dementia and their primary informal caregivers: a randomized clinical trial. International Journal of Nursing Studies: 2011

Specht et al., 2009 J. Specht, A. Bossen, G.R. Hall, B. Zimmerman and J. Russell, The effects of a dementia nurse care manager on improving caregiver outcomes outcomes, Am. J. Alzheimers Dis. Other Demen. 24 (2009), pp. 193-207. Full Text via CrossRef | View Record in Scopus | Cited By in Scopus (0)

Teunisse and Derix, 1991 S. Teunisse and M.M. Derix, Measurement of activities of daily living in patients with dementia living at home: development of a questionnaire, Tijdschr. Gerontol. Geriatr. 22 (2) (1991), pp. 53-59.

Thompson et al., 2007 C.A. Thompson, K. Spilsbury, J. Hall, Y. Birks, C. Barnes and J. Adamson, Systematic review of information and support interventions for caregivers of people with dementia, BMC Geriatr. 27 (2007), pp. 7-18.

Torti et al., 2004 F.M. Torti, L.P. Gwyther, S.D. Reed, J.Y. Freidman and K.A. Schulman, A multinational review of recent trends and reports in dementia caregiver burden, Alzheimer Dis. Assoc. Discord. 18 (2004), pp. 99-109.

Twisk, 2003 J.W.R. Twisk, Applied Longitudinal Data Analysis for Epidemiology: A Practical Guide, Cambridge University Press, Cambridge (2003).

Van der Zee and Sanderman, 1993 K.I. Van der Zee and R. Sanderman, Het meten van de gezondheidstoestand met de RAND-36: een handleiding, Noordelijk Centrum voor Gezondheidsvraagstukken, Groningen (1993) (in Dutch).

Vernooij-Dassen, 1993 Vernooij-Dassen, M., 1993. Dementia and Home-care. University of Nijmegen, PhD Thesis (in Dutch).

Vernooij-Dassen et al., 1999 M.J. Vernooij-Dassen, A.J. Felling, E. Brummelkamp, M.G. Dauzenberg, G.A. van den Bos and R. Grol, Assessment of caregiver's competence in dealing with the burden of caregiving for a dementia patient: a Short Sense of Competence Questionnaire (SSCQ) suitable for clinical practice, J. Am. Geriatr. Soc. 47 (2) (1999), pp. 256-257.

Vernooij-Dassen et al., 2005 M.J. Vernooij-Dassen, E.D. Moniz-Cook, R.T. Woods, J. de Lepeleire, A. Leuschner, O. Zanetti, J. de Rotrou, G. Kenny, M. Franco, V. Peters and S. Illiffe, Factors affecting timely recognition and diagnosis of dementia across Europe: from awareness to stigma, Int. J. Geriatr. Psychiatry 20 (4) (2005), pp. 377-386.

Vickrey et al., 2006 B.G. Vickrey, B.S. Mittman, K.I. Connor, M.L. Pearson, R.D. Della Penna, T.G. Ganiats, R.W. Demonte Jr., J. Chodosh, X. Cui, S. Vassar, N. Duan and M. Lee, The effect of a disease management intervention on quality and outcomes of dementia care: a randomized, controlled trial, Ann. Intern. Med. 145 (10) (2006), pp. 713-726. 
Jansen, A.P.D., Hout, H.P.J. van, Nijpels, G., Rijmen, F., Droës, R.M., Pot, A.M., Schellevis, F.G., Stalman, W.A.B., Marwijk, H.W.J. van. Effectiveness of case management among older adults with early symptoms of dementia and their primary informal caregivers: a randomized clinical trial. International Journal of Nursing Studies: 2011

\section{[TABLES AND FIGURES]}

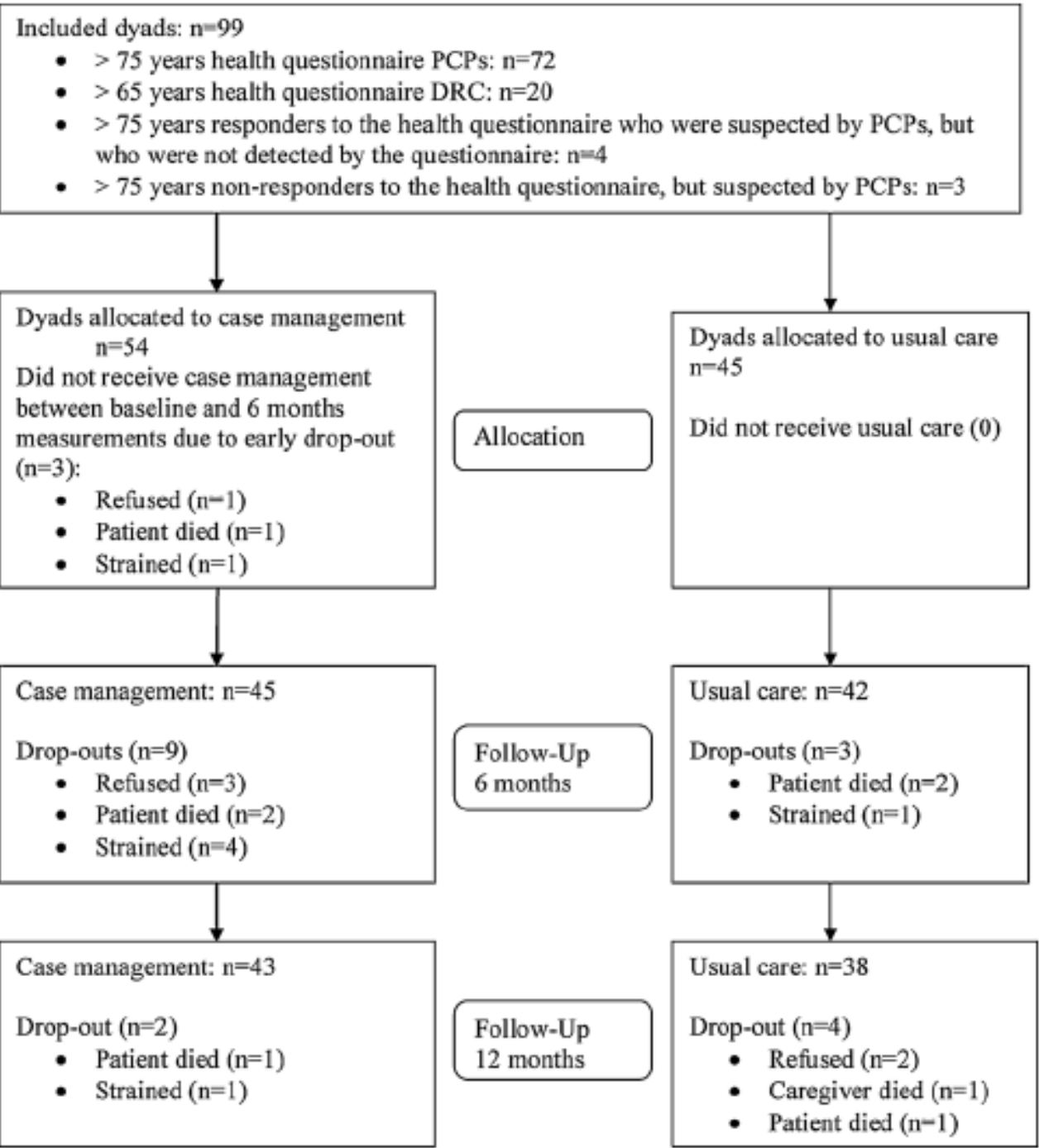

Fig. 1. Fow-chart of the study. PCPs, primary care physicians; DRC, primary care diabetic research center. 
Jansen, A.P.D., Hout, H.P.J. van, Nijpels, G., Rijmen, F., Droës, R.M., Pot, A.M., Schellevis, F.G., Stalman, W.A.B., Marwijk, H.W.J. van. Effectiveness of case management among older adults with early symptoms of dementia and their primary informal caregivers: a randomized clinical trial. International Journal of Nursing Studies: 2011

Table 1

Baseline characteristics of participating informal caregivers and persons with dementia symptoms.

\begin{tabular}{|c|c|c|c|c|c|}
\hline Characteristics & Unit of size & Case-management & $n=54$ & Usual care & $n=45$ \\
\hline \multicolumn{6}{|l|}{ Informal caregivers } \\
\hline \multicolumn{6}{|l|}{ Demographic charactenistics } \\
\hline Age & Mean (SD) & $63.6(13.8)$ & $n=51$ & $61.6(15.2)$ & $n=41$ \\
\hline Gender, female & Frequency & $36 / 54$ & $n=54$ & $33 / 45$ & $n=45$ \\
\hline Relation with the care recipient & Frequency & & $n=53$ & & $n=44$ \\
\hline Spouse & & $22 / 53$ & & $18 / 44$ & \\
\hline Child & & $26 / 53$ & & $22 / 44$ & \\
\hline Child in law & & $1 / 53$ & & $3 / 44$ & \\
\hline Other & & $4 / 53$ & & $1 / 44$ & \\
\hline Living together with the care recipient & Frequency & $27 / 54$ & $n=54$ & $19 / 44$ & $n=44$ \\
\hline Months spent on caring, median & $\begin{array}{l}\text { Median (25th. } \\
75 \text { th percentile) }\end{array}$ & $24.0(15.0,36.0)$ & $n=39$ & $33.0(23.0,48.0)$ & $n=29$ \\
\hline Hours spent on caring a week & $\begin{array}{l}\text { Median ( } 25 \text { th, } \\
75 \text { th percentile) }\end{array}$ & $7.0(3.4,67.5)$ & $n=38$ & $10.0(3.0,20.0)$ & $n=31$ \\
\hline Help from other persons & Frequency & $28 / 47$ & $n=47$ & $26 / 41$ & $n=41$ \\
\hline $\begin{array}{l}\text { Social support (SSL-1, subscale positive interactions: } \\
\text { 34-136f } \text { f }^{-4}\end{array}$ & Mean (SD) & $65.5(12.0)$ & $n=50$ & $73.2(16.7)$ & $n=41$ \\
\hline Educational level & Frequency & & $n=51$ & & $n-42$ \\
\hline Primary school or noeducation & & $7 / 51$ & & $7 / 42$ & \\
\hline Secondary & & $37 / 51$ & & $27 / 42$ & \\
\hline College, university & & $7 / 51$ & & $8 / 42$ & \\
\hline \multicolumn{6}{|l|}{ General (heait $h$ ) funcrioning } \\
\hline Self reported health, (very) good or excellent & Frequency & $35 / 51$ & $n=51$ & $30 / 42$ & $n-42$ \\
\hline Chronic disease, $\geq 1$ chronic diseases & Frequency & $36 / 51$ & $n-51$ & $25 / 42$ & $n-42$ \\
\hline Mastery (mastery. 7-35) ${ }^{c}$ & Mean (SD) & $25.1(4.9)$ & $n=48$ & $25.3(4.8)$ & $n-41$ \\
\hline (I)ADL functioning (GARS, $18-72)^{d}$ & Mean (SD) & $22.1(6.0)$ & $n-50$ & $223(8.7)$ & $n-42$ \\
\hline $\begin{array}{l}\text { Caregiver's distress associated with patient's neuropsychiatric } \\
\text { symptoms (NPI-Q distress, 0-60) }\end{array}$ & Mean (SD) & $7.4(7.6)$ & $n-50$ & $7.4(8.9)$ & $n-41$ \\
\hline \multicolumn{6}{|l|}{ Primary outcome measure } \\
\hline \multicolumn{6}{|l|}{ Caregiver's sense of competence (SCQ) } \\
\hline 1. Satisfaction with one's own performance (12-60f & Mean (SD) & $48.7(5.2)$ & $n=50$ & $49.8(7.7)$ & $n=43$ \\
\hline $\begin{array}{l}\text { 2. Consequences of involvement in care for the personal life } \\
\text { of the caregiver (a subscale of the SCQ, 8-40F }\end{array}$ & Mean (SD) & $28.4(5.8)$ & $n=50$ & $28.8(6.8)$ & $n=43$ \\
\hline $\begin{array}{l}\text { 3. Satisfaction with the older adult as a recipient } \\
\text { of care }(7-35)^{\text {ca }}\end{array}$ & Mean (SD) & $29.1(4.1)$ & $n=50$ & $30.9(4.3)$ & $n=43$ \\
\hline \multicolumn{6}{|l|}{ Secandary outcame measures } \\
\hline \multicolumn{6}{|l|}{ Quality of life (SF-36) } \\
\hline 1. Mental component summary $(0-100)^{\mathrm{f}} \mathrm{b}$ & Mean (SD) & $51.0(9.1)$ & $n=51$ & $47.6(9.9)$ & $n=42$ \\
\hline 2. Physical component summary $(0-100)^{\text {c) }}$ & Mean (SD) & $44.6(10.1)$ & $n-51$ & $48.0(11.6)$ & $n-42$ \\
\hline Depressive symptoms (CES-D, 0-60) & Mean (SD) & $10.6(5.9)$ & $n=50$ & $11.5(7.8)$ & $n=42$ \\
\hline Burden (SPPIC, 0-9) & Mean (SD) & $3.9(2.7)$ & $n-46$ & $3.3(2.6)$ & $n=39$ \\
\hline \multicolumn{6}{|l|}{ Care recipients } \\
\hline \multicolumn{6}{|l|}{ Demographic charactenistics } \\
\hline Age & Mean (SD) & $82.1(5.7)$ & $n=54$ & $81.0(6.5)$ & $n-45$ \\
\hline Gender, female & Frequency & $38 / 54$ & $n=54$ & $26 / 45$ & $n=45$ \\
\hline Cognitive functioning (MMSE, $0-30)^{\mathrm{f}}$ & Mean (SD) & $22.0(4.2)$ & $n=53$ & $22.7(3.8)$ & $n=43$ \\
\hline Cognitive functioning (7MS, $0-100)^{d}$ & $\begin{array}{l}\text { Median ( } 5 \text { th, } \\
10 \text { th percentile) }\end{array}$ & $100(64,83)$ & $n=53$ & $100(0,64)$ & $n-43$ \\
\hline Cognitive functioning (1QCODE by caregiver, $1-5)^{d}$ & Mean (SD) & $4.1(0.6)$ & $n=49$ & $4.1(0.6)$ & $n=42$ \\
\hline Months with cognitive symptoms ${ }^{4}$ & $\begin{array}{l}\text { median ( } 25 \text { th. } \\
75 \text { th percentile) }\end{array}$ & $24.0(16.3,36.0)$ & $n-40$ & $36.0(24.0,60.0)$ & $n=30$ \\
\hline $\begin{array}{l}\text { Severity of neuropsychiatric symptoms (NPI-Q } \\
\text { severity, 0-36) }\end{array}$ & Mean (SD) & $6.2(5.0)$ & $n=50$ & $6.2(6.2)$ & $n=41$ \\
\hline Initiative in daily living functioning (IDDD, 0-36) ${ }^{d}$ & Mean (SD) & $12.3(8.8)$ & $n-43$ & $11.4(8.2)$ & $n=39$ \\
\hline $\begin{array}{l}\text { Actual performance in daily living functioning } \\
\text { (IDDD, } 0-44)^{d}\end{array}$ & Mean (SD) & $14.1(10.0)$ & $n-45$ & $13.2(9.3)$ & $n-39$ \\
\hline Chronic disease, $\geq 1$ chronic diseases & Frequency & $44 / 54$ & $n=54$ & $31 / 44$ & $n=44$ \\
\hline Urinary incontinence & Frequency & $18 / 48$ & $n=48$ & $11 / 39$ & $n=39$ \\
\hline (Last) job level (nct housewife) & Frequency & & $n=26$ & & $n=28$ \\
\hline Unskilled jobs & & $1 / 26$ & & - & \\
\hline Semi-skilled jobs & & $15 / 26$ & & $13 / 29$ & \\
\hline Skilled jobs & & $10 / 26$ & & $11 / 29$ & \\
\hline Higher professional jobs & & - & & $1 / 29$ & \\
\hline Highly specialized jobs & & - & & $3 / 29$ & \\
\hline \multicolumn{6}{|l|}{ Secandary outcame measures } \\
\hline \multicolumn{6}{|l|}{ Quality of life (DQoLf } \\
\hline 1. Self-esteem (1-5) & Mean (SD) & $3.2(0.7)$ & $n=44$ & $3.3(0.7)$ & $n=38$ \\
\hline 2. Positive affect $(1-5)$ & Mean (SD) & $3.4(0.7)$ & $n-44$ & $3.5(0.6)$ & $n=37$ \\
\hline 3. Negative affect (1-5) & Mean (SD) & $2.5(0.7)$ & $n=44$ & $22(0.7)$ & $n=35$ \\
\hline
\end{tabular}


Jansen, A.P.D., Hout, H.P.J. van, Nijpels, G., Rijmen, F., Droës, R.M., Pot, A.M., Schellevis, F.G., Stalman, W.A.B., Marwijk, H.W.J. van. Effectiveness of case management among older adults with early symptoms of dementia and their primary informal caregivers: a randomized clinical trial. International Journal of Nursing Studies: 2011

Table 1 (Continued)

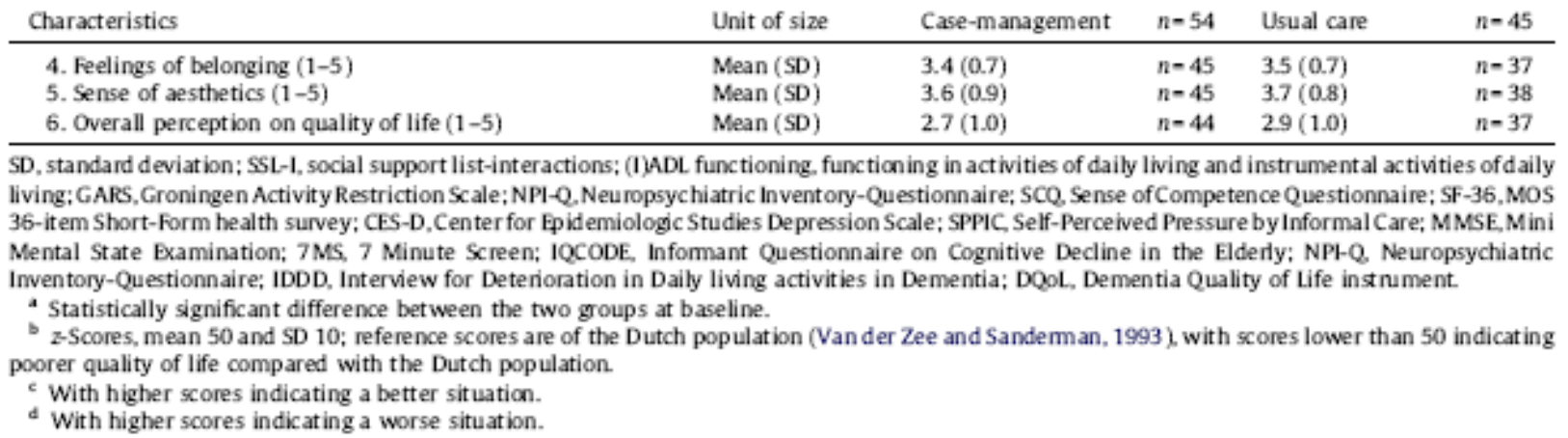


Jansen, A.P.D., Hout, H.P.J. van, Nijpels, G., Rijmen, F., Droës, R.M., Pot, A.M., Schellevis, F.G., Stalman, W.A.B., Marwijk, H.W.J. van. Effectiveness of case management among older adults with early symptoms of dementia and their primary informal caregivers: a randomized clinical trial. International Journal of Nursing Studies: 2011

Table 2

Effects of case-management and usual care at baseline, at 6 months and at 12 months.

\begin{tabular}{|c|c|c|c|}
\hline Outcome measures & $\begin{array}{l}\text { Case-management } \\
n=54 \text { (mean) }\end{array}$ & $\begin{array}{l}\text { Usual care } \\
n=45 \text { (mean) }\end{array}$ & Linear Mixed Model ${ }^{d}$ \\
\hline \multicolumn{4}{|l|}{ Primary outcome measure } \\
\hline \multicolumn{4}{|l|}{ Caregiver's sense of competence (SCQ) } \\
\hline \multicolumn{3}{|l|}{ 1. Satisfaction with one's own performance $(12-60)^{\text {b }}$} & Stable over time in both groups \\
\hline Baseline & 48.6 & 49.7 & $\mathrm{~T}: F=1.01 ; P=.140$ \\
\hline 6 months & 46.6 & 49.9 & $G: F=2.16 ; P=.120$ \\
\hline 12 months & 47.4 & 48.4 & $\mathrm{~T} \times \mathrm{G}: F=2.48 ; P=.105$ \\
\hline \multicolumn{3}{|l|}{ 2. Consequences of involvement in care $(8-40)^{\mathrm{b}}$} & Decline over time in both groups \\
\hline Baseline & 28.1 & 28.8 & $\mathrm{~T}: F=4.74 ; P=.013$ \\
\hline 6 months & 28.0 & 29.6 & $\mathrm{G}: F=0.68 ; P=.460$ \\
\hline 12 months & 27.1 & 27.7 & $\mathrm{~T} \times \mathrm{G}: F=0.55 ; P=.494$ \\
\hline \multicolumn{3}{|l|}{ 3. Satisfaction with the older adult $(7-35)^{\mathrm{b}}$} & Decline over time in both groups \\
\hline Baseline & 29.0 & 30.8 & $\mathrm{~T}: F=7.72 ; P=.001$ \\
\hline 6 months & 28.4 & 29.6 & $\mathrm{G}: F=3.12 ; P=.081$ \\
\hline 12 months & 27.7 & 29.0 & $\mathrm{~T} \times \mathrm{G}: F=0.44 ; P=.647$ \\
\hline \multicolumn{4}{|l|}{ Secondary outcome measures } \\
\hline \multicolumn{4}{|l|}{ Caregiver's quality of life (SF-36) $)^{\mathrm{b} . \mathrm{a}}$} \\
\hline \multicolumn{3}{|l|}{ 1. Mental component summary $(0-100)$} & Stable over time in both groups \\
\hline Baseline & 51.0 & 48.0 & $\mathrm{~T}: F=1.38 ; P=.257$ \\
\hline 6 months & 48.7 & 49.1 & $G: F=0.33 ; P=.568$ \\
\hline 12 months & 48.2 & 47.7 & $\mathrm{~T} \times \mathrm{G}: F=1.37 ; P=.260$ \\
\hline \multicolumn{3}{|l|}{ 2. Physical component summary $(0-100)$} & Stable over time in both groups \\
\hline Baseline & 44.5 & 48.0 & $\mathrm{~T}: F=0.41 ; P=.667$ \\
\hline 6 months & 45.5 & 46.5 & $\mathrm{G}: F=1.11 ; P=.294$ \\
\hline 12 months & 46.0 & 47.5 & $\mathrm{~T} \times \mathrm{G}: F=1.06 ; P=.353$ \\
\hline \multicolumn{3}{|l|}{ Caregiver's depressive symptoms (CES-D, $0-60)^{c}$} & Stable over time in both groups \\
\hline Baseline & 10.6 & 11.2 & $\mathrm{~T}: F=0.14 ; P=.867$ \\
\hline 6 months & 11.9 & 9.7 & $\mathrm{G}: F=0.18 ; P=.669$ \\
\hline 12 months & 11.2 & 11.2 & $\mathrm{~T} \times \mathrm{G}: F=1.80 ; P=.172$ \\
\hline \multicolumn{3}{|l|}{ Caregiver's burden (SPPIC, 0-9) } & Stable over time in both groups \\
\hline Baseline & 3.9 & 3.3 & $\mathrm{~T}: F=3.05 ; P=.053$ \\
\hline 6 months & 3.8 & 2.7 & $\mathrm{G}: F=2.89 ; P=.092$ \\
\hline 12 months & 4.2 & 3.3 & $\mathrm{~T} \times \mathrm{G}: F=0.72 ; P=.492$ \\
\hline \multicolumn{4}{|l|}{ Care recipient's Quality of life (DQoL) ${ }^{\mathbf{b}}$} \\
\hline \multicolumn{3}{|l|}{ 1. Self-esteem (1-5) } & Stable over time in both groups \\
\hline Baseline & 3.3 & 3.3 & $\mathrm{~T}: F=1.50 ; P=.230$ \\
\hline 6 months & 3.2 & 3.3 & $G: F=0.01 ; P=.981$ \\
\hline 12 months & 3.4 & 3.3 & $\mathrm{~T} \times \mathrm{G}: F=0.45 ; P=.638$ \\
\hline \multicolumn{3}{|l|}{ 2. Positive affect $(1-5)$} & Stable over time in both groups \\
\hline Baseline & 3.4 & 3.4 & $\mathrm{~T}: F=0.17 ; P=.845$ \\
\hline 6 months & 3.4 & 3.5 & $\mathrm{G}: F=0.02 ; P=.894$ \\
\hline 12 months & 3.5 & 3.4 & $\mathrm{~T} \times \mathrm{G}: F=2.53 ; P=.087$ \\
\hline \multicolumn{3}{|l|}{ 3. Negative affect $(1-5)$} & Stable over time in both groups \\
\hline Baseline & 2.5 & 2.2 & $\mathrm{~T}: F=1.20 ; P=.309$ \\
\hline 6 months & 2.5 & 2.2 & $G: F=3.40 ; P=.069$ \\
\hline 12 months & 2.3 & 2.2 & $\mathrm{~T} \times \mathrm{G}: F=0.29 ; P=.747$ \\
\hline \multicolumn{3}{|l|}{ 4. Sense of aesthetics $(1-5)$} & Decline over time in both groups \\
\hline Baseline & 3.6 & 3.7 & $\mathrm{~T}: F=3.32 ; P=.042$ \\
\hline 6 months & 3.3 & 3.5 & $G: F=0.16 ; P=.690$ \\
\hline 12 months & 3.4 & 3.3 & $\mathrm{~T} \times \mathrm{G}: F=0.48 ; P=.621$ \\
\hline \multicolumn{3}{|l|}{ 5. Feelings of belonging $(1-5)$} & Stable over time in both groups \\
\hline Baseline & 3.4 & 3.4 & $\mathrm{~T}: F=0.31 ; P=.735$ \\
\hline 6 months & 3.3 & 3.4 & $G: F=0.13 ; P=.715$ \\
\hline 12 months & 3.4 & 3.3 & $\mathrm{~T} \times \mathrm{G}: F=0.75 ; P=.476$ \\
\hline \multicolumn{3}{|l|}{ 6. Overall perception on quality of life $(1-5)$} & Stable over time in both groups \\
\hline Baseline & 2.7 & 2.9 & $\mathrm{~T}: F=1.45 ; P=.241$ \\
\hline 6 months & 2.8 & 3.0 & $\mathrm{G}: F=0.14 ; P=.710$ \\
\hline 12 months & 2.8 & 2.6 & $\mathrm{~T} \times \mathrm{G}: F=0.96 ; P=.387$ \\
\hline
\end{tabular}

SCQ Sense of Competence Questionnaire; SF-36, MOS 36-item Short-Form health survey; CES-D, Center for Epidemiologic Studies Depression Scale; SPPIC, Self-Perceived Pressure by Informal Care; DQoL, Dementia Quality of Life instrument.

a $z$-Scores, mean 50 and SD 10; reference scores are of the Dutch population (Van der Zee and Sanderman, 1993), with scores lower than 50 indicating poorer quality of life compared with the Dutch population.

b With higher scores indicating a better situation.

c With higher scores indicating a worse situation.

${ }^{d}$ The analysis yields restricted maximum likelihood estimates for the effects of time, treatment group and the time $\times$ treatment group interaction. The effectiveness of treatment is flagged by a statistically significant time $\times$ treatment group interaction: the two groups have different patterns of change in outcome measurements over time. At baseline, no differences are expected because of the randomization, but after 6 or 12 months the two groups will differ if usual care and case management differ in effectiveness. A significant time effect alone means that the 2 groups have similar patterns of change in outcomes over time, and hence that there is no differential effect of the treatment. 
Jansen, A.P.D., Hout, H.P.J. van, Nijpels, G., Rijmen, F., Droës, R.M., Pot, A.M., Schellevis, F.G., Stalman, W.A.B., Marwijk, H.W.J. van. Effectiveness of case management among older adults with early symptoms of dementia and their primary informal caregivers: a randomized clinical trial. International Journal of Nursing Studies: 2011

Table 3

Care received by the informal caregivers and by the care recipients in the case-management group and the usual care group.

\begin{tabular}{|c|c|c|}
\hline Care received during 12 months of participating & $\begin{array}{l}\text { Case-management } n=36 \\
\text { (out of } n=43 \text { ) mean, median (range) }\end{array}$ & $\begin{array}{l}\text { Usual care } n=33 \text { (out of } n=38 \text { ) } \\
\text { mean, median (range) }\end{array}$ \\
\hline \multicolumn{3}{|l|}{ Informal caregivers } \\
\hline $\begin{array}{l}\text { Primary care physician (number of consults by telephone, } \\
\text { home-visits, and at practice) }\end{array}$ & $3.9,3.0(0-16)$ & $3.9,3.0(0-20)$ \\
\hline Home care (hours a weak) & $2.7,0(0-50)$ & $0.9,0(0-9)$ \\
\hline Outpatient geriatric/psychiatric team (number of consults) & $0.03,0(0-1)$ & $0.8,0(0-18)$ \\
\hline Dinner service (number of days) & $4.8,0(0-156)$ & $6.1,0(0-182)$ \\
\hline Medical specialist (number of consults) & $1.8,0(0-23)$ & $1.7,0(0-8)$ \\
\hline Dutch support center for informal caregivers (number of consults) & Never & Never \\
\hline Information by phone for informal caregivers (number of consults) & $0.3,0(0-10)$ & Never \\
\hline Respite care (number of days) & $0.06,0(0-2)$ & Never \\
\hline Temporary institutionalizations (number of days) & $2.3,0(0-56)$ & $0.2,0(0-7)$ \\
\hline Physiotherapist (number of consults) & $3.9,0(0-35)$ & $2.2,0(0-23)$ \\
\hline Homeopath (number of consults) & Never & $0.3,0(0-9)$ \\
\hline Psychologist (number of consults) & Never & $0.3,0(0-11)$ \\
\hline Social worker (number of consults) & $0.1,0(0-3)$ & Never \\
\hline Care received during 12 months of participating & $\begin{array}{l}\text { Case-management } \\
n=37 \text { (out of } n=43 \text { ) }\end{array}$ & $\begin{array}{l}\text { Usual care } \\
n=33 \text { (out of } n=38 \text { ) }\end{array}$ \\
\hline \multicolumn{3}{|l|}{ Care recipients } \\
\hline $\begin{array}{l}\text { Primary care physician (number of consults by telephone, } \\
\text { home-visits, and at practice) }\end{array}$ & $8.3,5.0(0-58)$ & $6.6,4.0(0-40)$ \\
\hline Home care (hours a weak) & $6.0,3.0(0-52.0)$ & $4.0,2.2(0-21.5)$ \\
\hline $\begin{array}{l}\text { Outpatient geriatric/psychiatric team/diagnostic service } \\
\text { (number of consults) }\end{array}$ & $0.5,0(0-6)$ & $0.2,0(0-5)$ \\
\hline Day care (number of days) & $19.4,0(0-182)$ & $15.0,0(0-364)$ \\
\hline Dinner service (number of days) & $33.5,0(0-362)$ & $62.1,0(0-364)$ \\
\hline Medical specialist (number of consults) & $2.7,1.0(0-19)$ & $3.3,2.0(0-14)$ \\
\hline Physiotherapist (number of consults) & $6.2,0(0-52)$ & $6.2,0(0-100)$ \\
\hline Homeopath (number of consults) & Never & $0.03,0(0-1)$ \\
\hline Psychologist (number of consults) & Never & $0.03,0(0-1)$ \\
\hline Social worker (number of consults) & $0.05,0(0-2)$ & $0.03,0(0-1)$ \\
\hline
\end{tabular}


Jansen, A.P.D., Hout, H.P.J. van, Nijpels, G., Rijmen, F., Droës, R.M., Pot, A.M., Schellevis, F.G., Stalman, W.A.B., Marwijk, H.W.J. van. Effectiveness of case management among older adults with early symptoms of dementia and their primary informal caregivers: a randomized clinical trial. International Journal of Nursing Studies: 2011

Table 4

Process measures: informal caregiver's satisfaction with the quality of care and intervention fidelity.

\begin{tabular}{|c|c|c|c|}
\hline \multicolumn{4}{|c|}{ Informal caregivers' satisfaction with the quality of care (QUOTE-elderly), $n=38$} \\
\hline Aspects of care & Importance ${ }^{\mathrm{a}}(\mathrm{SD})$ & Performance ${ }^{b}$ & Quality $^{c}$ \\
\hline Understanding of patients' problems & $2.7(0.7)$ & 0.07 & 0.19 \\
\hline Work efficiently & $3.1(0.6)$ & 0 & 0 \\
\hline Patient decides about treatment/help & $3.0(0.7)$ & 0 & 0 \\
\hline Take patient seriously & $3.2(0.7)$ & 0 & 0 \\
\hline Keep appointments punctually & $2.9(0.6)$ & 0 & 0 \\
\hline Good care co-ordination & $3.0(0.6)$ & 0.12 & 0.36 \\
\hline Friendly attitude & $3.0(0.7)$ & 0 & 0 \\
\hline Enough time during consultations & $2.6(0.6)$ & 0.08 & 0.21 \\
\hline Cover when my regular help is absent & $2.5(0.8)$ & 0.04 & 0.10 \\
\hline Discuss problems/mistakes & $3.0(0.6)$ & 0.04 & 0.12 \\
\hline Home help for as many hours needed & $2.5(0.7)$ & 0 & 0 \\
\hline \multicolumn{4}{|c|}{ Intervention fidelity from the nurses' perspective: elements of the intervention (not) executed } \\
\hline Elements & Nurse 1 & Nurse 2 & Nurse 3 \\
\hline \multicolumn{4}{|l|}{ Obligatory } \\
\hline Administration of RAI-HC & Yes & Yes & Yes \\
\hline Discussing health problems & Yes & Probably ${ }^{\mathrm{d}}$ & Probably ${ }^{\mathrm{d}}$ \\
\hline Ranking health problems into a hierarchy of urgency & Probably $^{d}$ & Probably ${ }^{d}$ & Probably ${ }^{d}$ \\
\hline $\begin{array}{l}\text { Exploring the caregiver situation during the } \\
\text { second home visit }\end{array}$ & Yes & Yes & Yes \\
\hline Leaving a dossier at the patient's home & $\begin{array}{l}\text { Only if long-lasting } \\
\text { care was necessary }\end{array}$ & Yes & Yes \\
\hline Leaving a visiting card and telephone number & Yes & Yes & Yes \\
\hline Leaving a guide for informal caregivers & $\begin{array}{l}\text { Yes, if she had the } \\
\text { guides with her }\end{array}$ & Yes & Yes \\
\hline $\begin{array}{l}\text { Leaving behind a form to register care received } \\
\text { and appointments with health care professionals }\end{array}$ & $\begin{array}{l}\text { Only if she had the } \\
\text { forms with her }\end{array}$ & Yes & Yes \\
\hline $\begin{array}{l}\text { discussing how to proceed with the intervention } \\
\text { after two visits: }\end{array}$ & $\begin{array}{l}\text { How to proceed } \\
\text { depended on } \\
\text { the care needs }\end{array}$ & $\begin{array}{l}\text { How to proceed } \\
\text { depended on the } \\
\text { care needs }\end{array}$ & $\begin{array}{l}\text { How to proceed } \\
\text { depended on } \\
\text { the care needs }\end{array}$ \\
\hline $\begin{array}{l}\text { Monitoring the situation every } 3 \text { months (even in } \\
\text { case of few problems) }\end{array}$ & No & Yes & $\begin{array}{l}\text { Possibly, the situation } \\
\text { of the informal } \\
\text { caregiver was not } \\
\text { monitored if the } \\
\text { patient's situation } \\
\text { was stable }^{d}\end{array}$ \\
\hline $\begin{array}{l}\text { The nurse contacted the general practitioner to } \\
\text { inform her/him about the situation }\end{array}$ & $\begin{array}{l}\text { Seldom, general } \\
\text { practitioners } \\
\text { were not in for it }\end{array}$ & $\begin{array}{l}\text { Yes, but not al } \\
\text { general practitioners } \\
\text { were in for it }\end{array}$ & $\begin{array}{l}\text { Yes and all the general } \\
\text { practitioners were } \\
\text { in for it }\end{array}$ \\
\hline \multicolumn{4}{|l|}{ Tailor-made } \\
\hline Organising a family-meeting & Never & Yes, in 1 participant & Yes, in 1 participant \\
\hline $\begin{array}{l}\text { Referring to other health care professionals and } \\
\text { monitoring the anticipated effect }\end{array}$ & $\begin{array}{l}\text { After referring she } \\
\text { did not actively } \\
\text { check the } \\
\text { anticipated effect }\end{array}$ & Yes & Yes \\
\hline $\begin{array}{l}\text { Referring to diagnostic services and monitoring } \\
\text { the anticipated effect }\end{array}$ & Yes & Yes & Yes \\
\hline
\end{tabular}

SD, standard deviation; QUOTE-elderly, Quality of Care Through the patients' Eyes questionnaire, version aimed at elderly; RAI-HC, Resident Assessment Instrument Home Care.

a Importance index = mean score on a scale ranging from 1 (not important) to 4 (extremely important)

b Performance index = proportion of caregivers not (really) satisfied with the performance of the nurse.

c Quality impact index = importance score multiplied by the performance score. This index indicates quality aspects that can be improved.

d The nurses did not explicitly tell this, but we abstracted this out of their interview. 